\title{
Enhanced Sludge Processing of HLW: Hydrothermal Oxidation of Chromium, Technetium, and Complexants by Nitrate
}

\author{
Mid-Year Progress Report
}

\author{
Steven Buelow \\ Los Alamos National Laboratory \\ June 1, 1997
}

\section{Goals of Project:}

Treatment of High Level Waste (HLW) is the second most costly problem identified by OEM. In order to minimize costs of disposal, the volume of HLW requiring vitrification and long term storage must be reduced. Methods for efficient separation of chromium from waste sludges, such as the Hanford Tank Wastes (HTW), are key to achieving this goal since the allowed level of chromium in high level glass controls waste loading. At concentrations above 0.5 to $1.0 \mathrm{wt}$. $\%$ chromium prevents proper vitrification of the waste. Chromium in sludges most likely exists as extremely insoluble oxides and minerals, with chromium in the plus III oxidation state [1]. In order to solubilize and separate it from other sludge components, $\mathrm{Cr}$ (III) must be oxidized to the more soluble $\mathrm{Cr}(\mathrm{VI})$ state. Efficient separation of chromium from HLW could produce an estimated savings of \$3.4B[2]. Additionally, the efficient separation of technetium [3], TRU, and other metals may require the reformulation of solids to free trapped species as well as the destruction of organic complexants. New chemical processes are needed to separate chromium and other metals from tank wastes. Ideally they should not utilize additional reagents which would increase waste volume or require subsequent removal.

The goal of this project is to apply hydrothermal processing for enhanced chromium separation from HLW sludges. Initially, we seek to develop a fundamental understanding of chromium speciation, oxidation/reduction and dissolution kinetics, reaction mechanisms, and transport properties under hydrothermal conditions in both simple and complex salt solutions. We also wish to evaluate the potential of hydrothermal processing for enhanced separations of technetium and TRU by examining technetium and TRU speciation at hydrothermal conditions optimal for chromium dissolution.

1. D.L. Blanchard, S.D. Conradson, N.J. Hess, and P.K. Melethil, "Sludge Component Speciation: Summary Final Report," PNL Report TWRSPP-95-048, Pacific Northwest Laboratory, 1995.

2. R.A. Watrous, WHC, "Feed Specification for HLW Vitrification," Technical Presentation to Waste Processing Architecture Group, Nov. 1, 1994.

3. N.C. Schroeder, S.D. Radzinski, J.R. Ball, K.R. Ashley, S.L. Cobb, B. Cutrell, J.M. Adams, C. Johnson, and G.D. Whitener, "Technetium Partitioning for the Hanford Tank Waste Remediation System,” LANL Report LA-UR-95-4440, Los Alamos National Laboratory, 1995.

Technical Description of Work: 
The ability to process and separate chromium and other metals from radioactive waste in a hydrothermal reaction medium depends on oxidation and reduction rates, solids dissolution rates, the equilibrium species present, and the phase behavior of the reaction mixture as a function of pressure, temperature, ionic strength, mineral form, and $\mathrm{pH}$. For this project, we will examine these fundamental aspects of metal oxide chemistry at hydrothermal conditions. The majority of the experiments will investigate chromium chemistry at temperatures and pressures ranging between 50 and $550{ }^{\circ} \mathrm{C}$ and 10 and 1000 bar. Later, we will also examine the reactions of technecium (Tc) and transuranics (TRU) at selected reaction conditions to determine speciation and partitioning of theses species in the reaction effluents. We will use experimental methods similar to those developed and proven during our earlier studies of oxidation reactions of organics in HLW simulants [1,2]. The information gathered will be used to elucidate reaction pathways and develop models for dissolution chemistry in new pressure and temperature regimes.

Chromium Oxidation: The dissolution kinetics for chromium oxide reactions with nitrate/nitrite in a variety of solutions containing inorganic salts and organic complexing agents is being studied. We are determining reaction kinetics and product distributions as a function of reaction conditions (pressure, temperature, $\mathrm{pH}$, and reaction time) using batch and flow reactors and ex situ analysis of the reaction products. Gas chromatography, high pressure liquid chromatography, inductively coupled plasma spectroscopy, and absorption spectroscopy are being used to identify and quantify products.

Our current experiments are examining the reactions of chromium with nitrate/nitrite under hydrothermal conditions in simple mixtures (water, nitrate, hydroxide) in order to understand the fundamental chemistry. Batch, stirred batch, and packed bed reactors have been constructed and are being used to measure the oxidation/dissolution rate for $\mathrm{Cr}_{2} \mathrm{O}_{3}$. Later this year we will examine the effects of additional waste components (EDTA, aluminate, carbonate, phosphate, chloride, nickel, iron) on reaction chemistry, speciation, and partitioning in the process effluent. This data will be used to develop and validate models for hydrothermal processing for improved separation in complex mixtures and to provide data for comparison of the baseline alkaline leach technology.

Diffusion and ion conductance parameters are being measured for important reacting species. Diffusion and conductance coefficients in hydrothermal regimes are generally unknown. We are measuring diffusion parameters using two methods we have recently developed for measurements in hydrothermal systems, the laser-induced grating technique [3,4] and Taylor-Aris dispersion [5]. We have measured mass diffusion coefficients for sodium nitrate, the reacting species on the chromium oxide surface, in various salt mixtures. Comparison with observed dissolution rates will show whether diffusion or surface reaction dominates dissolution. Measurements for chromate should also be possible; diffusion of products away from the particle surface is an important model parameter in some regimes [6]. We have developed a simple Pt electrode cell to determine electrical conductances of nitrate solutions. The conductance values give a preliminary evaluation of ion association and speciation for the hydrothermal solutions. 
Later this year, in situ spectroscopy will be used to help elucidate the reaction mechanisms for metal and nitrogen species by monitoring the appearance and disappearance of reactants, intermediates and product species. Raman spectroscopy in the homogeneous hydrothermal fluid will enable us to follow the loss of nitrate/nitrite due to reaction and the growth of various chromium oxide species, some of which may be transient and not amenable to post-mortem analysis of reaction effluents. Chromium compounds have distinct vibrational signatures and should be readily distinguished.

Absorption spectroscopy in the uv-visible region will also be used, as chromium compounds have strong absorptions. Although there is a limitation due to overlapping bands, the sensitivity should be much higher than Raman spectroscopy. The decomposition of nitrate to nitrite, for example, can be monitored by uv spectroscopy. In particular, Raman and UV absorption spectroscopy will be used to follow the disappearance of reactants (EDTA, nitrate, nitrite) and the appearance of intermediates and products $\left(\mathrm{N}_{2} \mathrm{O}, \mathrm{N}_{2}, \mathrm{NH}\right.$, nitrite, nitrate, $\mathrm{Cr}(\mathrm{VI}), \mathrm{H}_{2}, \mathrm{CO}, \mathrm{CO}$,).

Oxyanion species formed in solution and adsorbed on the surface will be identified by spectroscopic investigation, and the solubilities of these species will be determined by observing phase equilibria using custom made optical cells. The surfaces of solid reactants will be analyzed by surface spectroscopy and microscopy after reaction to determine morphology changes.

Results from our experiments will be used to develop a model for chromium dissolution in HLW mixtures similar to those stored at Hanford. In our previous study of organic oxidation in HLW simulants, we modeled the kinetics with a simple expression dependent on the total organic concentration, with the nitrate and nitrite species lumped into a total $\mathrm{NO}_{\mathbf{X}}{ }^{-}$concentration. We also found that the presence of aluminum, phosphate, sulfate and most other waste components did not significantly change the rates of formation or the distribution of reaction products $[1,2,7]$. Results from our study of chromium oxidation will be used to identify the important elementary reaction pathways, quantify the effects of temperature, pressure, $\mathrm{pH}$, and mixture composition on the rates of these elementary reactions, formulate a reaction model, and validate model predictions.

The solubility of the product chromate or dichromate species is expected to be important for the dissolution reaction. We will determine solubility limits and other phase boundaries for sodium chromate and dichromate mixtures using an optical cell [8]. The solution will be pumped into the cell, pressurized, and heated to temperatures above the pressure and temperature of interest. The pressure will then be decreased. Phase transitions during the heat-up and depressurization will be monitored by visual observation through the diamond windows, as we have previously done for sodium nitrate and sodium carbonate hydrothermal solutions [8]. In the strong electrolyte solutions we will be studying, we expect some of the critical temperatures to exceed $600^{\circ} \mathrm{C}$. The concentrated salt solutions can undergo liquid-gas, liquid-liquid, or liquidsolid phase transitions. It is important to know the location of these transitions because the diffusion constants may decrease considerably near them. Proper interpretation of our data requires knowledge of both the number of phases and their transport properties.

Technetium and Actinide Chemistry: The oxidation and dissolution of chromium may affect the separability of Tc and TRU elements. To better evaluate the usefulness of 
hydrothermal processing for HLW, we will examine the speciation and partitioning of TC and TRU in Hanford tank wastes and tank waste simulants at conditions optimum for chromium removal. We wish to determine whether hydrothermal processing of HLW for chromium removal will have beneficial or adverse effects on the removal of Tc and TRU

These experiments will be performed using both batch and flow reactors. The flow reactors used will be similar to those previously described [9]. The batch reactors will be small autoclaves that can be rapidly heated and cooled. Currently it is difficult to obtain sufficient quantities of actual waste to conduct continuous flow experiments. Experiments with actual waste will most likely be completed in batch reactors. Simulant studies will be performed using both batch and flow systems. The results of these experiments will be used to discern any significant changes in product distributions between the two processing methods. These studies will be conducted in collaboration with Norm Schroeder of LANL who is currently examining the speciation of Tc in Hanford waste samples and evaluating the efficiency of separation of various ion exchange resins [9]. He will provide the samples for hydrothermal processing and perform the post-mortem analysis of Tc products. We will perform the hydrothermal processing and determine the TRU speciation. We will also perform hydrothermal experiments with rhenium compounds, which are good chemical surrogates for technetium [9]. If the technetium species present in Hanford waste are identified during the course of our project, we will be able to make up mixtures of these species at known concentrations and determine rates of oxidation to $\mathrm{TcO}_{4}^{-}$.

The results from these experiments may have additional significance. Current proposals for separating technetium from waste, such as Hanford tank waste, rely on the element being present in the fully oxidized pertechnetate form, $\mathrm{TcO}_{4}^{-}$. Recent experiments show that much of the technetium is in the form of some unidentified, lowervalent complex not easily oxidized by hydrogen peroxide [9]. Hydrothermal oxidation may be capable of converting these other forms to $\mathrm{TcO}_{4}^{-}$, since strong oxidizing agents (nitric acid, hydrogen peroxide) can accomplish this at room temperature [10].

1. R. Oldenborg, S. J. Buelow, G. Anderson, G. Baca, R. Brewer, P. C. Dell'Orco, B. R. Foy, K. Knutsen, L. A. Le, R. McInroy, R. McFarland, S. Moore, J.M. Robinson, P. Rodgers, R. Shaw, and E. Wilmanns, "Evaluation of IPM Selection Criteria for Hydrothermal Processing," LA-UR-94-1945, LANL( 1994).

2. B. R. Foy, P. C. Dell'Orco, W. D. Breshears, S. J. Buelow, J. Ely, K. A. Funk, L. A. Le, R. E. McInroy, R. Oldenborg, J. M. Robinson, M. Sedillo, and E. G. Wilmanns, "Hydrothermal Kinetics of Organic and Nitrate/Nitrite Destruction for Hanford Tank Waste Simulant," Los Alamos Unclassified Report No. LA-UR-94:3174, Los Alamos National Laboratory (1994).

3. T. Butenhoff, M. Goemans, S. Buelow, J. Chem. Phys. (1996) in press.

4. T. Butenhoff, Int. J. Thermophys., 16, 1, 1995.

5. M. G. E. Goemans, E. F. Gloyna and S. J. Buelow, "Mass Transfer in SCWO Processes: Molecular Diffusion and Mass Transfer Coefficients of Inorganic Nitrate Species in Sub- and Supercritical Water", Proceedings of the Second International Symposium on Environmental Applications of Advanced Oxidation Technologies, Electrical Power Research Institute, Palo Alto (1996) in press. 
6. M.C. Segal and W.C. Williams, J. Chem. Soc. Faraday Trans. 82, 3245 (1986).

7. R. Oldenborg, J.M. Robinson, S.J. Buelow, R.B. Dyer, G. Anderson, P.C. Dell'Orco, K. Funk, E. Wilmanns, and K. Knutsen, "Hydrothermal Processing of Inorganic Components of Hanford Tank Wastes", LA-UR-94:3233, LANL (1994).

8. G.K. Anderson, Physical Chemistry of Aqueous Systems, Proceedings of the 12th International Conference on the Properties of Water and Steam, H. J. White, J. V. Sengers, D.B. Neumann, and J. C. Bellows, eds., (Begell House, NY) p. 573-580 (1995).

9. N.C. Schroeder, S.D. Radzinski, J.R. Ball, K.R. Ashley, S.L. Cobb, B. Cutrell, J.M. Adams, C. Johnson, and G.D. Whitener, "Technetium Partitioning for the Hanford Tank Waste Remediation System," LANL Report LA-UR-95-4440, Los Alamos National Laboratory, 1995.

10. A.F. Cotton and G. Wilkinson, Advanced Inorganic Chemistry, Wiley: New York, 3rd ed,. 1972, p. 981.

\section{Accomplishments to Date:}

Work on this project began in September 1996. During this first year, the research has focused on four areas:

(1) Review and evaluation of scientific literature on the chemistry and reactions of chromium in aqueous solutions.

(2) The design and construction of batch, stirred batch, and packed bed reactors.

(3) The measurement of reaction rates for chromium oxide in simple mixtures of water, nitrates, and hydroxides.

(4) The measurement of the diffusion coefficients and electrical conductances of aqueous inorganic nitrate solutions.

Below we present a summary of the accomplishments and results in each area.

(1) Evaluation of Literature: A literature review and analysis has been completed on the preparation and aqueous chemistry of chromium oxide. Thermodynamically, the forms of chromium oxide depend on the temperature and its environment. Kubota [1] found that the decomposition of $\mathrm{CrO}_{3}$ under oxygen environment from 200 to $600^{\circ} \mathrm{C}$ follows the chain from $\mathrm{CrO}_{3}\left(<210^{\circ} \mathrm{C}\right), \mathrm{Cr}_{3} \mathrm{O}_{8}\left(210-280^{\circ} \mathrm{C}\right), \mathrm{Cr}_{2} \mathrm{O}_{5}\left(280-370^{\circ} \mathrm{C}\right), \mathrm{CrO}_{2}\left(370-450^{\circ} \mathrm{C}\right)$, and $\mathrm{Cr}_{2} \mathrm{O}_{3}\left(>450^{\circ} \mathrm{C}\right)$. The reverse reaction $\mathrm{Cr}_{2} \mathrm{O}_{3} \rightarrow \mathrm{CrO}_{2}$ is possible at high pressure of oxygen [2]. Chromium oxide in aqueous condition was reported by Kruss and Tammana [3]. They claimed that hydrated $\mathrm{Cr}(\mathrm{OH})_{3}$ undergo a transition to $\mathrm{CrO}(\mathrm{OH})$ at temperature as low as $70^{\circ} \mathrm{C}$. $\mathrm{CrO}(\mathrm{OH})$ is very stable until the system temperature reaches $540^{\circ} \mathrm{C}$ where $\mathrm{Cr}_{2} \mathrm{O}_{3}$ is formed. The crystalline phase of $\mathrm{CrOOH}$ in the system of chromium oxide-water was verified by Laubengaver and McCune [4]. This hydrothermal treatment also affects the texture of this hydroxide, such as surface area, pore volume, pore size, and water content [5]. Carruthers et al. [6] reported that the calcination of chromium oxide gels in oxygen will form $\mathrm{CrOOH}$ at $250^{\circ} \mathrm{C}$. However, they also found that as much as $45 \%$ of chromium is in $\mathrm{Cr}(\mathrm{VI})$ form, depending on calcined temperature. The aging and properties of chromium oxide gels are also complicated. They are studied by Spiccia and Marty [7], Bleuzen et al. [8], and Shu [9]. 
The dissolution of chromium oxide with different reagents was reported. Segal and Williams [10] studied the oxidative dissolution of chromium (III) oxide (calcined at $1000^{\circ} \mathrm{C}$ under argon) by large excess of potassium permanganate at temperature ranging from 43 to $140^{\circ} \mathrm{C}$. They found that the dissolution rate depends on the temperature, concentration of oxidant, and $\mathrm{pH}$. The calcined temperature affecting dissolution rate has been reported [ 11-14], mostly in acid conditions. However, there is no report concerning the possible forms of chromium oxide other than $\mathrm{Cr}$ (III) in dissolution study.

$\mathrm{Cr}(\mathrm{III})$ and $\mathrm{Cr}(\mathrm{VI})$ are both found in Hanford tank sludge [15]. $\mathrm{Cr}$ (III) in tank sludge is proposed as chromium in $\mathrm{Cr}: \mathrm{FeOOH}$ and with disordered oxygen. The form of the chromium in the tank wastes is not well known and so at this time it is not possible to prepare tank wastes simulants which we are confident will mimic tank sludge. To help overcome this shortcoming we will examine a variety of simulant formulations.

(2) Design and construction of reactors: Three new experimental apparatus for study of the dissolution of chromium oxide were built for this project. These include: small, teflon-lined, batch reactors; a stirred batch reactor system; and a packed-bed flow reactor system.

The small batch reactors are teflon coated swagelock bulkhead unions. The reactors are heated for reaction times varying from hours to days using a fluidized sand bath.

The stirred batch reactor is a $300 \mathrm{ml}$ high pressure SS316 vessel. The reactor is nickel coated to minimize the leaching of chromium from the stainless steel. The thermocouple and magnetic stir bar are teflon coated, while teflon tubing and filters are used in the sampling system. Temperature and pressure transducers monitor reactor conditions. Oxidation reaction are initiated by rapidly pumping the oxidant into the reactor after it has reached operating temperature. Samples are removed periodically (minutes to hours) to determine reaction kinetics.

The packed-bed flow reactor is shown in Figure 1. The pressure vessel is a (5/16" id x 9/16" od) high pressure SS316 tube. A concentric nickel liner runs the length of the pressure vessel and is sealed to the pressure vessel at both ends. High pressure distilled water flows between the pressure vessel and nickel liner walls to balance the pressure in the liner. Chromium oxide samples are loaded into the central section of the liner. The soluble reagents are pressurized, heated, and pumped through the solid packed bed. Filters at the exit of the bed keep the solid material stationary. The reactor effluent is cooled, depressurized, collected and analyzed. The reaction time for the soluble material is determined by mass flow rate, bed free-volume, and the density of the reaction mixture at reaction temperature and pressure. The reaction time for the solid material is determined by the total flow duration. At the end of the experiment the bed material is removed and analyzed. The bed material may contain both unreacted starting material and insoluble products that could not be transported out of the reactor. 

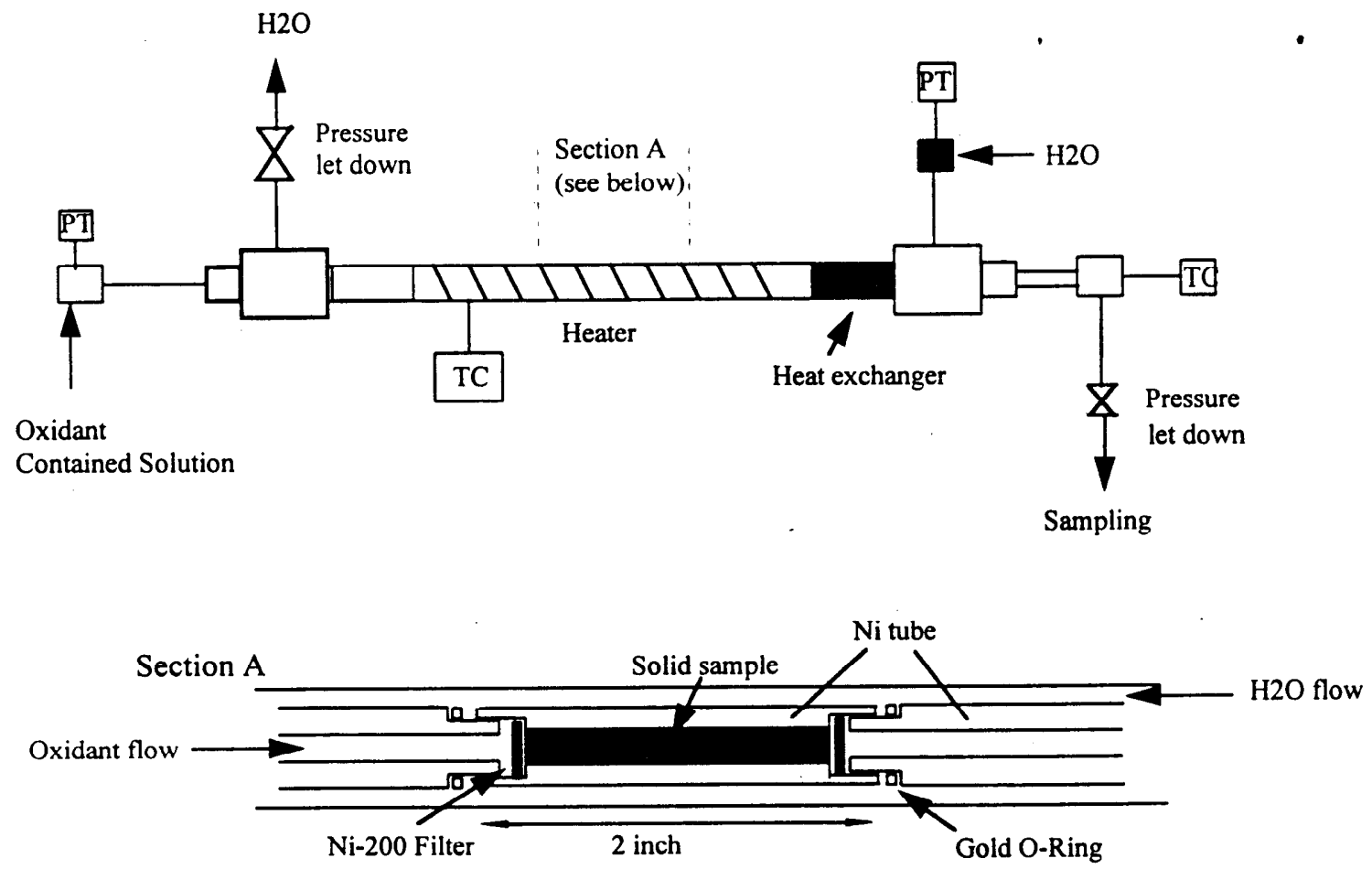

Figure 1. Schematic of packed-bed flow reactor.

In collaboration with two other separate Los Alamos projects examining-the hydrothermal oxidation of combustible wastes, batch and flow reactor systems were built and installed in the Los Alamos plutonium facility. These reactors will be used by this project in the third year to study the chemistry of Tc and TRU at selected hydrothermal conditions.

(3) Kinetics experiments: Initial kinetics experiments were performed using the small teflon lined batch reactors heated in a sand bath. Hydrated chromium oxide was prepared by adding sodium hydroxide solution to a chromium nitrate solution at room temperature. The resulting gel was washed and then dried at $120^{\circ} \mathrm{C}$ for 24 hours. Separate samples were calcined at $120,200,300,450,700{ }^{\circ} \mathrm{C}$ for 5 hours in air.

Dissolution/reaction experiments for the samples calcined at the various temperatures were performed at 25,100 , and $200{ }^{\circ} \mathrm{C}$. The samples were reacted separately with deionized water, $\mathrm{NaNO}_{3} / \mathrm{NaOH}$, and nitric acid solutions. The results for the reactions with deionized water are shown in figure 2 . These results are typical. The trends in $\mathrm{Cr}$ concentration versus calcine temperature are similar in the other experiments. The use of nitric acid or $\mathrm{NaNO}_{3} / \mathrm{NaOH}$ did not significantly increase the amount of $\mathrm{Cr}$ dissolved. The samples calcined at $120^{\circ} \mathrm{C}$ show little dissolution of $\mathrm{Cr}$. The greatest dissolution occurs for the samples calcined in the 200 to $300^{\circ} \mathrm{C}$ range. These results suggest that at higher calcine temperatures $\left(>120^{\circ} \mathrm{C}\right)$ some of the $\mathrm{Cr}$ (III) is converted to $\mathrm{Cr}(\mathrm{VI})$ via the reaction:

$$
\text { a } \mathrm{Cr}_{2} \mathrm{O}_{3} \cdot \mathrm{xH}_{2} \mathrm{O}+\mathrm{b} \mathrm{O}_{2}+\mathrm{q}---->\mathrm{c} \mathrm{H}_{2} \mathrm{CrO}_{4}
$$


The $\mathrm{Cr}(\mathrm{VI})$ produced during calcination easily dissolves, leaving the insoluble $\mathrm{Cr}_{2} \mathrm{O}_{3}$ behind. Calcination in an inert atmosphere of argon or nitrogen should reduce the amount of $\mathrm{Cr}(\mathrm{VI})$ in the samples.

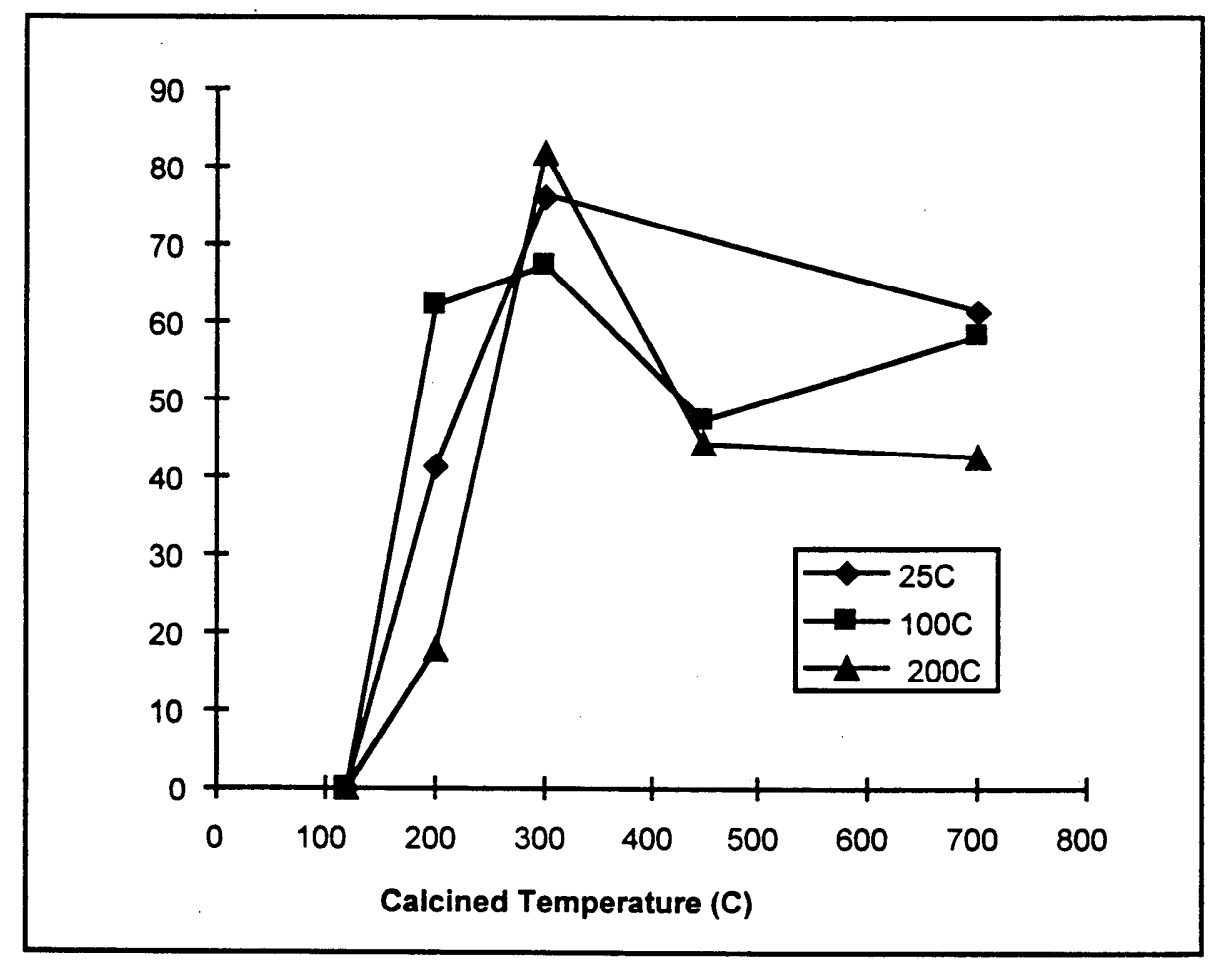

Figure 2. Total chromium concentration in solution after reaction for 4 hours, at the indicated temperatures, as a function of the temperature used to calcine the chromium oxide.

(4) Diffusion Experiments: The molecular diffusion of inorganic nitrate species in sub and supercritical water were measured at temperatures between 200 and $500^{\circ} \mathrm{C}$, and pressures between 250 and 100 bar. In the concentrated salt solutions, the critical slowing down of the diffusion was significant as far as 300 bar from the phase transition pressures. Ordinary binary mass diffusion was about 15 times faster at higher temperatures than at $25^{\circ} \mathrm{C}$. Experimental results agree well with predictions from StokesEinstein equation, where the diffusing species is represented as a hydrated contact pair. A manuscript summarizing the results of this work has been prepared and submitted to International Journal of Thermophysics. A paper discussing the work will be presented at the Thirteenth Symposium on Thermalphysical Properties.

The electrical conductances of aqueous solutions of inorganic nitrates at 25 to $505^{\circ} \mathrm{C}$, and 100 to 490 bar were measured. The alkali nitrates show series behavior similar to the alkali chloride series: the electrical conductance decreases with decreasing cation radius. This seemingly paradoxical result is due to the stronger electric field and, hence, the greater tendency for ion pairing and larger solvation spheres associated with 
the smaller cations. Nearly complete ion association is observed at low-density supercritical conditions. A manuscript summarizing the results of this work has been prepared and accepted for publication in the Journal of Supercritical Fluids.

\section{Projections:}

The milestones for the first year of the project are:

Complete measurements of chromium oxidation kinetics using flow and packedbed experiments to determine processing conditions for chromium and form of rate expression.

Complete preliminary phase behavior measurements to determine regions of product solubility in bulk fluid, and phases for nitrate oxidizer.

Complete preliminary Raman spectroscopy experiments on chromium species in fluid formed by dissolution reactions.

We anticipate that during the first year we will complete the work described in these milestones. We have already initiated the diffusion experiments which were originally planned for the second year and have built and installed the reactors needed for the Tc and TRU studies planned for the third year. We are ahead of our initial schedule in both of these areas. Currently we plan to examine the relation between chromium oxide morphology (as determined by the perpetration conditions) and the reaction kinetics in greater detail than we had initially anticipated. This change will extend some of the kinetics measurements into the second year of the project.

During the remainder of this year, we will continue our kinetics experiments on both simple and complex mixtures, and complete our preliminary phase behavior and Raman spectroscopy experiments.

\section{Funding:}

Spending for the project is as initially planned. To date we have spent $\$ 218 \mathrm{~K}$ of our $\$ 332 \mathrm{~K}$ first year budget. Spending was low during the first two months of the project. The post-dot and graduate student hired to work on the project arrived in October. The spending rate increased in the December 96 -May 97 period while the new reactor systems were being built. Now that most of the construction is complete, spending will slow during the last third of the project year and the project will finish the first year close to or less than projected budget.

\section{Issues/Problems:}

At this time, no serious problems have developed. The strong dependence of the reaction chemistry on the chromium oxide morphology has caused an increase in the amount of effort we will spend in this area. This should not effect the overall schedule. 


\section{Corrective Actions:}

None at this time.

\section{Additional Information:}

Collaborative work on this project is being performed with Professors Earnest Gloyna and Keith Johnston of The University of Texas at Austin, and Professor Tony Arrington of Furman University. A graduate student from Professor Gloyna's group will spend six months at Los Alamos measuring chromium dissolution kinetics. A post-dot from Professor Johnston group plans to visit Los Alamos to perform spectroscopic experiments. Professor Arrington and two undergraduate students from Furman will spend this summer at Los Alamos performing kinetics and spectroscopic experiments.

Two manuscripts have been prepared based on work performed for this project:

M.G.E. Goemans, T. J. Funk, M. A. Sedillo, S. J. Buelow, and Graydon K. Anderson, "Electrical conductances of aqueous solutions of inorganic nitrates ate $25-505^{\circ} \mathrm{C}$ and 100 490 bar." accepted for publication in the Journal of Supercritical Fluids.

M.G.E. Goemans, T.J. Butenhoff, E. F. Gloyna, G. K. Anderson, and S. J. Buelow, "Molecular diffusion of inorganic nitrate species and ketones in subcritical and supercritical water." Submitted to the International Journal of Thermophysics.

1. B. Kubota, "Decomposition of Higher Oxides of Chromium Under Various Pressures of Oxygen.” J. Am. Soc., 44 (5), 247 (1961).

2. Y. Shibasaki, F. Kanamaru, M. Koizumi, S. Kume, J. Am. Ceram. Soc., 56 (5), 248 (1973).

3. G. G. Kruss, and E. G. Tammana, Zei. anorg. Allgem. Chemie. 276, 275 (1954).

4. A. W. Laubengaver, and H. W. McCune, "New Crystalline Phases in the System Chromium (III) Oxide-Water.” J. Amer. Chem. Soc. 74, 2362 (1952).

5. N. T. Okopnaya, and V. M. Chertov, "Hydrothermal Modification of Chromium Hydroxide.” Katal. Katal. 1079 (1978).

6. J. D. Carruthers, J. Fenerty, and K.S. W Sing, "Bulk and Surface Properties of Chromium Oxide Gels." in The Reactivity of Solids. Proc 6th. Inter. Symp. on the Reactivity of Solids, ed. J. W. Mitchell, Wiley-Inter. Science, New York, 1969.

7. L. Spiccia, and W. Marty, "The Fate of 'Active' Chromium Hydroxide, $\mathrm{Cr}(\mathrm{OH}) 3 \bullet 3 \mathrm{H} 2 \mathrm{O}$, in Aqueous Suspension. Study of the Chemical Changes Involved in Its Aging." Inorg. Chem. 25 (3), 26 (1986).

8. A. Bleuzen, P. Barboux, J. Livage, and F. Garcia, "Solution Synthesis of Chromium Oxides: Gelation or Precipitation?” Eur. J. Solid State Inorg. Chem. 33, 1025 (1996).

9. P. Shu, "Gelation Mechanism of Chromium (III).” ACS Symp. Ser. 396, 137 (1989). 
10. M. G. Segal, and W. J. Williams, "Kinetics of Metal Oxide Dissolution." J. Chem. Soc., Faraday Trans. 1, 82, 3245 (1986).

11. L. G. Rodenas, P. J. Morando, and M. A. Blesa, "Acid and Oxidative Dissolution of Coprecipitated Iron-Chromium Oxides.” Can. J. Chem. 71, 771 (1993).

12. G. B. Reartes, P. J. Morando, and M. A. Blesa, "Reactivity of Chromium Oxide in Aqueous Solutions. 2. Acid Dissolution.” Langmuir 11, 2277 (1995).

13. A. Mills, and P. J. Sawunyama, "Oxidative Dissolution of Chromium (III) Oxides by Metaperiodate Ions in Perchloric Acid.” Chem. Soc., Faraday Trans., 89(18), 3389 ( 1993 ).

14. M. A. Blesa, P. J. Morando, and A. E. Regazzoni, "Chromium Oxide." in Chemical Dissolution of Metal Oxides. CRC Press, 1994.

15. D.L. Blanchard, S.D. Conradson, N.J. Hess, and P.K. Melethil, "Sludge Component Speciation: Summary Final Report," PNL Report TWRSPP-95-048, Pacific Northwest Laboratory, 1995. 